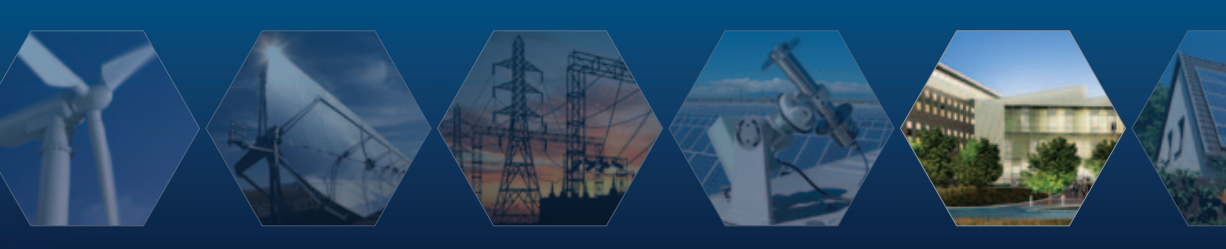

Electricity, Resources, \& Building Systems Integration

\title{
Opt-E-Plus Software for Commercial Building Optimization
}

The Advanced Commercial Buildings Research group at the National Renewable Energy Laboratory (NREL) develops and utilizes advanced energy modeling tools to help architects, engineers, and facility managers understand the energy implications of their designs and maximize the efficiency of their buildings. Whole-building energy modeling and optimization are important tools for achieving energy-efficient, cost-effective buildings.

To maximize the energy-savings potential of a building, NREL researchers use Opt-E-Plus, a powerful tool that automatically runs thousands of simulations and identifies design options that provide the most economical energy savings.

\section{Automating the Simulation and Analyses Process}

Optimizing a building's design to achieve cost-effective energy savings is challenging because of the many variables involved. Manually running energy simulations to analyze all the possible system interactions is time consuming and may not return the best results. With funding from the U.S. Department of Energy's Building Technologies Program, NREL developed Opt-E-Plus to automate this process. Opt-E-Plus offers these benefits:

- Saves time. Opt-E-Plus creates multiple parametrics and automatically runs thousands of simulations-reducing a process that by hand could take weeks to just hours.

- Uses a comprehensive modeling engine. Opt-E-Plus uses EnergyPlus, a robust, whole-building energy simulation program, to run each energy model. EnergyPlus has modules to address a variety of technologies such as tubular daylighting devices and underfloor air distribution. Additionally, new technologies can be added to the EnergyPlus engine. Learn more at www.energyplus.gov.

- Accounts for the complex interaction of building systems. Opt-E-Plus ensures the recommended design options favor a whole-building approach. This is due to EnergyPlus' powerful modeling capabilities and Opt-E-Plus' ability to manage thousands of simulations.

- Provides better results. Opt-E-Plus replaces a trial and error process with an automated approach that analyzes many simulations to identify energy-saving options.

Opt-E-Plus automatically runs a large number of energy simulations $-3,000$ per building on average-and then provides a set of optimal building features and characteristics that can help meet the design goals for the building.

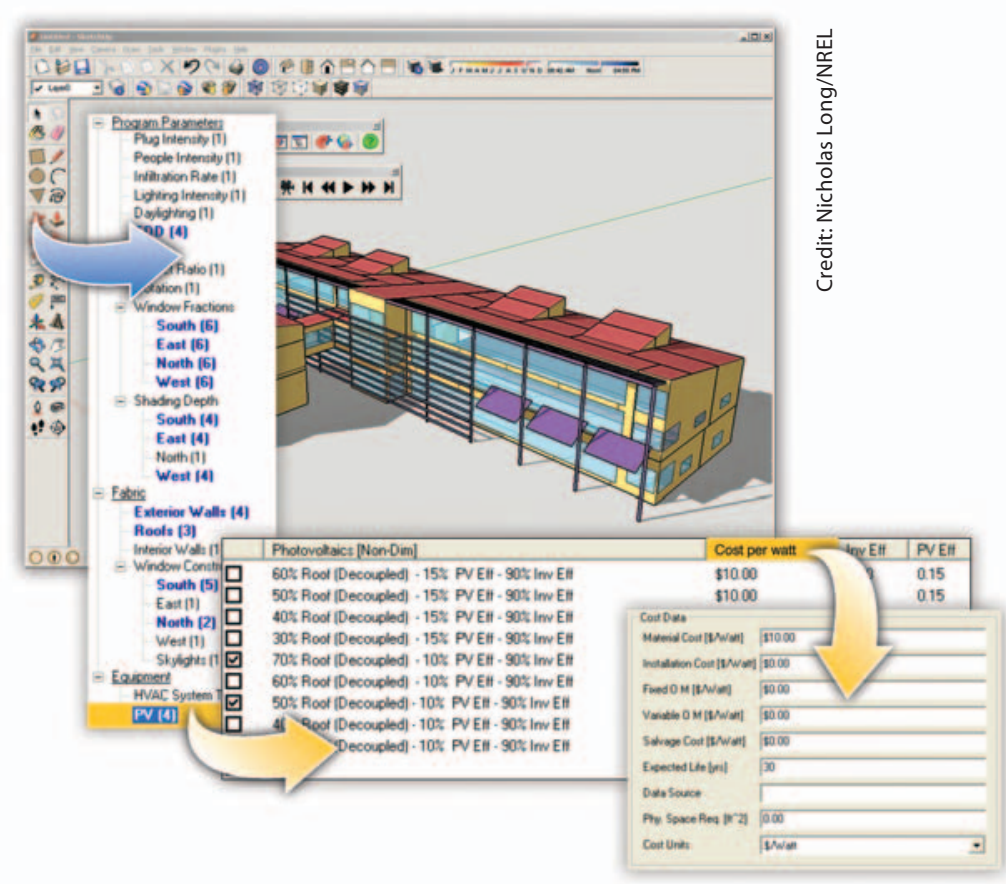

The NREL researcher, based on input from the project team, defines parameters of the building in Opt-E-Plus. Here, a building model created using OpenStudio, which can be imported into Opt-E-Plus, provides the starting point. The list shows some of the 40 parameters used. By selecting PV from the list, the NREL researcher can specify the type of $P V$ used and modify cost data.

\section{Providing Options to Meet Design Goals}

Opt-E-Plus was developed by NREL to help determine costeffective, energy-efficient building strategies quickly, taking into account the many factors involved in the design process. Based on design goals, Opt-E-Plus automatically:

- launches energy simulations

- analyzes simulation results

- alters variables based on the analyses

- launches new sets of simulations. 
The result of this process is a set of optimal solutions that designers can use in their decision making process. NREL uses this tool extensively when working with industry partners to identify the most effective solutions to reduce energy consumption in commercial buildings.

\section{How Opt-E-Plus Works}

Following are the key steps in using Opt-E-Plus:

(1) NREL researcher enters key inputs. Energy modeling simulations are based on parameters defined by the NREL researcher and the project team. Through Opt-E-Plus' building creation wizard, NREL researchers select options for as many as 40 major design parameters such as:

- Design performance criteria-goals based on cost and energy performance

- Location-climate zone, site orientation

- Structural characteristics-window-to-wall ratio, number of stories, geometry of the building

- Planned renewable energy use-photovoltaics, solar thermal, ground-source heat pump

- Building systems-lighting, ventilation, heating, cooling

- Occupancy-number of occupants, peak hours

- Plus many more.

Opt-E-Plus can import EnergyPlus files to automatically populate many of these parameters. Additionally, building models created using OpenStudio, a plugin that combines the drawing capabilities of SketchUp and the modeling of EnergyPlus, can be brought into Opt-E-Plus. Learn more about OpenStudio at www.energyplus.gov/openstudio.cfm.

2) Opt-E-Plus runs and analyzes simulations. Using EnergyPlus, Opt-E-Plus automatically runs hour-by-hour, physically detailed energy simulations based on the inputs. Opt-E-Plus determines which design options are to be simulated and then analyzes the results based on the performance objectives. After Opt-E-Plus runs initial simulations, it analyzes which options to keep and which to change and then launches a new set of simulations. Opt-E-Plus executes about 3,000 simulations, the average for a building design, in about 12 hours.

\section{(3) Opt-E-Plus evaluates codes and standards. Opt-E-Plus} can automatically apply codes and standards to a building to determine the design impact. These guidelines are based on the American Society of Heating, Refrigerating, and Air-Conditioning Engineers 90.1 standards. If the building is meant for multiple locations, Opt-E-Plus can provide design information for each site based on the standards for that area.

(4) Opt-E-Plus summarizes the results. Opt-E-Plus identifies the set of possible design strategies and technologies for a project and then summarizes the results. Results include

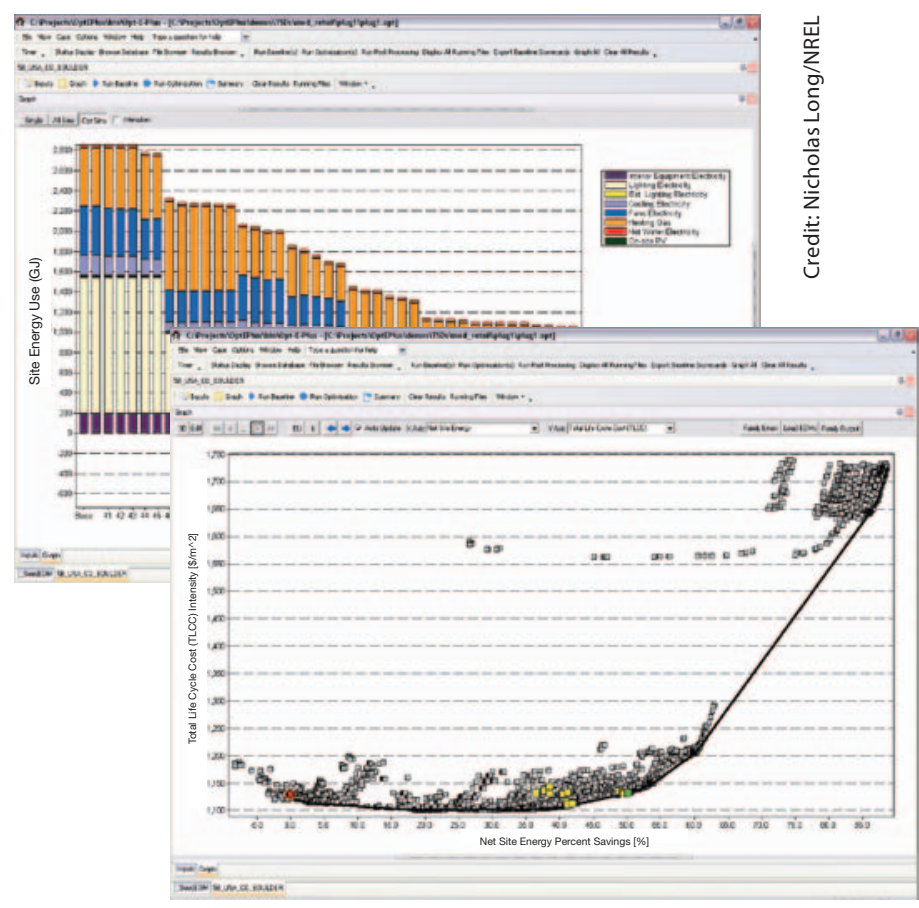

A results browser renders all the simulations on a chart of percent energy savings versus percent cost savings. Each point on the graph represents a simulation using different values. Opt-E-Plus offers detailed annual site energy use results for each simulation.

not only building characteristics, but also the financial and carbon impacts for each design option.

Cost data is built into the Opt-E-Plus database and provides information such as the life cycle costs, simple payback, and the net present value of design paths. To determine cost data, NREL consulted practicing architects and engineers along with cost data books which included regional adjustment factors. Cost data can be updated and changed as necessary.

\section{Results and Uses for Opt-E-Plus}

Opt-E-Plus offers significant benefits by automatically identifying a set of optimal design solutions to achieve cost-effective energy savings. The combined power of the simulation and optimization engines simplifies a cumbersome process. This tool, and the invaluable results it offers, will help move the industry toward net-zero energy buildings.

\section{To get information about working with NREL and learn more about Opt-E-Plus, contact Nicholas Long at Nicholas.Long@nrel.gov.}

Front page header images: Globe, iStock; Wind Turbine, iStock; Solar Trough, NREL/PIX 14381; Power

Lines, iStock; Solar Radiation Monitor, Tom Stoffel/PIX 15554; RSF Building image, NREL/PIX 16250; Solar Panels on roof, iStock

\section{National Renewable Energy Laboratory}

1617 Cole Boulevard, Golden, Colorado 80401-3305

303-275-3000 • www.nrel.gov

Printed with a renewable-source ink on paper containing at least $50 \%$ wastepaper, including $10 \%$ post consumer waste.
NREL is a national laboratory of the U.S. Department of Energy Office of Energy Efficiency and Renewable Energy Operated by the Alliance for Sustainable Energy, LLC 